Revista Española de Derecho Internacional Sección ESTUDIOS Vol. 68/2, julio-diciembre 2016, Madrid, pp. 23-49 http://dx.doi.org/10.17103/redi.68.2.2016.1.01 (C) 2016 Asociación de Profesores de Derecho Internacional y Relaciones Internacionales ISSN: 0034-9380; E-ISSN: 2387-1253

\section{ESTUDIOS}

\title{
UNA RENOVADA DIMENSIÓN DE LOS CONFLICTOS INTERNOS: LA LEY 5/2015 DE DERECHO CIVIL VASCO Y LA INTERACCIÓN ENTRE BLOQUES NORMATIVOS
}

\author{
Juan José Álvarez RuBio* \\ Catedrático de Derecho internacional privado \\ Universidad del País Vasco UPV/EHU
}

SUMARIO: 1. CONSIDERACIONES INTRODUCTORIAS.-2. LA LEY 5/2015, VÍA PARA EL DESARROLLO Y MODERNIZACIÓN DEL DERECHO CIVIL VASCO.-2.1. Bases competenciales y dimensión histórica.-2.2. Conflictos de leyes internos en el ámbito del País Vasco.-2.2.1. Precedentes normativos.-2.2.2. Técnica normativa empleada en la Ley 5/2015.-2.3. La vecindad civil vasca, piedra angular de la nueva ley.-3. EL ÁMBITO DEL DERECHO PÚBLICO AUTONÓMICO.-4. CONSIDERACIONES FINALES.

\section{CONSIDERACIONES INTRODUCTORIAS}

Las carencias del sistema español de Derecho internacional privado en la dimensión de los conflictos normativos internos impiden atender a la creciente complejidad jurídica derivada de nuestra pluralidad interna y permiten contextualizar estas reflexiones que, partiendo de la reciente reforma del Derecho civil vasco, persiguen realizar un análisis centrado en la necesidad de que el legislador interno español, tanto el estatal como los vinculados a los diversos sistemas jurídicos civiles especiales que conviven en seno del ordenamiento español, atiendan en sus futuros desarrollos normativos a la cada vez más relevante dimensión europea y pueda así encauzarse de forma armónica y coherente una acertada respuesta a la demanda de compatibilidad entre sistemas, más necesaria que nunca debido a la creciente interacción entre los diversos bloques normativos en presencia, derivados del actuar del legislador estatal, autonómico, foral, europeo y por último del ámbito convencional/internacional.

\footnotetext{
* Especializado en las áreas de Derecho marítimo, Derecho del comercio internacional y en el ámbito del Derecho de familia y de los conflictos internos. Ha liderado varios proyectos convocados por la Comisión Europea en ámbitos procesales y de ley aplicable, además del Atlas Judicial Europeo, y designado como experto independiente de la Comisión Europea para las áreas de libertad, seguridad y justicia.
} 
Debe tenerse presente que, tal y como señaló de forma muy atinada el Prof. Albert Font Segura ${ }^{1}$, la nota de internacionalidad de un supuesto litigioso en el que se cuestione conflictualmente la dimensión de la ley aplicable no elimina la pluralidad interna desde el punto de vista del sistema español, porque la determinación de cuál de los diferentes Derechos civiles españoles deba ser aplicado no es una cuestión que se plantee únicamente en supuestos interregionales sino que surge también y cada vez con más frecuencia en supuestos internacionales o intraeuropeos.

Nuestro sistema jurídico estatal se ubica en el grupo de los ordenamientos complejos o plurilegislativos ${ }^{2}$, caracterizado por la convivencia de diversos sistemas legislativos territoriales y por la presencia en su seno de conflictos internos de carácter interregional e interlocal ${ }^{3}$.

La estructura interna de nuestro sistema jurídico español queda integrada por todo un conjunto de normas destinado a resolver los llamados conflictos internos derivados de la coexistencia en nuestro país de los diversos ordenamientos civiles forales frente al Derecho común. La Constitución española de 6 de diciembre de $1978^{4}$ (en adelante, CE) constituye la regla base sobre la que se articula este nivel, que atiende a supuestos del llamado tráfico jurídico interregional y cuya delimitación ratione materiae revela un ámbito material centrado, hasta el presente, en específicos sectores del Derecho de familia (básicamente, matrimonio y sucesiones), junto a cuestiones vinculadas al concepto de propiedad y solo en la vertiente de ley aplicable.

Sin embargo, junto a la que cabría calificar como dimensión tradicional de los conflictos internos se añade en la actualidad otra, derivada del nuevo Derecho público económico elaborado por los respectivos legisladores autonómicos y que introduce un factor añadido de complejidad adicional en el sistema.

Desde esa dimensión interna del Derecho internacional privado (en adelante, DIPr) el art. 149.1.8 de la CE se traduce en la opción por un sistema estatal y, por tanto, uniforme, de Derecho interregional. Tal teórica unidad del sistema de solución de conflictos, junto a otros principios estructurales del sistema (como la igualdad o paridad entre los diversos ordenamientos

${ }^{1}$ Font Segura, A., «La pluralidad interna visita el reino del Derecho internacional privado. Comentario a la Resolución de la Direcció General de dret i Entitas Juridiques de 18 de septiembre de 2006», In Dret, 2007, núm. 2, pp. 3-5.

2 Sobre el particular, véase Zabalo Escudero, M. E., «El Derecho aplicable a las situaciones privadas internacionales en los ordenamientos plurales», en Forner i Delaygua, J. J., González Beilfuss, C. y ViÑAS FARré, R. (coords.), Entre Bruselas y La Haya. Estudios sobre la unificación internacional y regional del Derecho Internacional Privado. Liber Amicorum Alegría Borrás, Madrid, Marcial Pons, 2013, p. 899.

3 Sobre dicha realidad jurídica, véase entre otros IrIARTe Ángel, J. L., Propiedad y Derecho internacional. Los conflictos internos en el sistema español, Fundación registral (Colegio de registradores de la propiedad y mercantiles de España), 2007, pp. 133-163; ÁlVAREz RuBIo, J. J., Las normas de derecho interregional de la Ley 3/1992, de 1 de julio, de Derecho civil foral del país vasco, Oñati, Instituto Vasco de Administración Pública, 1995.

4 BOE núm. 311, de 29 de diciembre de 1978. 
civiles coexistentes), con incidencia en el ámbito de problemas de Derecho privado, ha sido ya objeto de interpretación por parte del Tribunal Constitucional (en adelante, TC) estableciendo los parámetros hermenéuticos básicos para delimitar los límites del legislador estatal y determinar el grado de discrecionalidad de este en ejercicio de su facultad de configuración del sistema de solución de tales conflictos internos.

Este gira, en ausencia de una específica Ley de Derecho interregional, en torno al art. 16 del Código Civil ${ }^{5}$ (en adelante, CC), cuyas líneas básicas se articulan sobre la base de un principio de remisión a las normas de DIPr (con ciertas excepciones) y el establecimiento de la vecindad civil como criterio de sujeción personal a los distintos ordenamientos civiles y teórico único punto de conexión. La vecindad civil constituye un elemento básico para resolver los conflictos de leyes en el ámbito interregional en cuanto principio general de vinculación y como técnica para determinar la sujeción a un determinado ordenamiento civil.

Y cabe afirmar que, en realidad, carecemos de un verdadero sistema de Derecho interregional, lo cual conduce a una permanente judicialización de tales conflictos normativo/competenciales internos.

El debate troncal o principal de estas reflexiones reside en analizar cómo responder a la particularidad que caracteriza al Derecho civil vasco, no exclusiva o privativa de él pero sí especialmente agudizada en su caso, concretada en la concurrencia de diversos subordenamientos locales o comarcales dentro del mismo ámbito territorial de la Comunidad Autónoma. ¿Debe interpretarse el alcance de la competencia estatal prevista en el art. 149.1.8 de la CE en el sentido de englobar o adscribir bajo la misma categoría competencial las normas orientadas a resolver tales conflictos normativos interlocales, o debe por el contrario entenderse que las Comunidades Autónomas (en adelante, CCAA) en las que concurra tal singular circunstancia tienen competencia para poder dictar normas para resolverlos?

La previsión específica y única del art. 10.5 de la Ley Orgánica 3/1979, de 18 de diciembre, de Estatuto de Autonomía para el País Vasco ${ }^{6}$ (en adelante EAPV), que forma parte del bloque de constitucionalidad, ¿ampara o da cobertura a esta segunda posible vía de interpretación, posibilitando que las CCAA tengan competencia para aprobar normas que pretendan resolver los conflictos de leyes intracomunitarios que se materializan dentro de ellas?

\section{LA LEY 5/2015, VÍA PARA EL DESARROLLO Y MODERNIZACIÓN DEL DERECHO CIVIL VASCO}

La nueva ley culmina una primera fase del proceso de actualización y modernización del Derecho civil vasco. Esta nueva norma, calificable de au-

\footnotetext{
5 Gaceta de 25 de julio de 1889.

6 BOE núm. 306, de 22 de diciembre de 1979.
} 
daz y prudente al mismo tiempo, sienta sólidos cimientos para garantizar un crecimiento orgánico del sistema jurídico privado vasco al superar la versión descriptiva de la Ley 3/1992, de 1 de julio, del Parlamento Vasco, del Derecho civil foral del País Vasco ${ }^{7}$ (en adelante, Ley 3/1992) y hacer posible por vez primera en su historia un corpus normativo jurídico privado propio para todo el País Vasco, respetando, a su vez, las singularidades forales territoriales preexistentes.

Combinar el respeto a la tradición y a las raíces de tal Derecho foral con la labor de actualización representaba un primer gran reto legislativo. El nuevo texto normativo trabaja en esa doble dimensión: una ad intra, marcando la pauta conflictual normativa necesaria para resolver los denominados conflictos interlocales derivados de la coexistencia interna en su seno de diversos ordenamientos propios y otra vertiente ad extra, porque la nueva ley mira a Europa, con el ejemplo del Reglamento europeo sobre sucesiones como piedra de toque.

La labor legislativa realizada no se basa en una mera extensión imperativa del ámbito de tales instituciones forales sino que logra fundamentar su aplicabilidad en atención a su propia calidad y sentido común, en cuanto ordenación razonable que va a operar como la verdadera fuerza persuasiva del renovado sistema jurídico. Solo así podrá lograrse, y esta nueva ley es un paso decisivo cara a lograr tal objetivo, un Derecho civil vasco vertebrado mediante unos principios decantados históricamente a través de la costumbre que ensamblen todo el orden jurídico vasco.

La nueva ley recoge toda una serie de principios generales que han de inspirar como cánones hermenéuticos de obligada referencia su proceso de aplicación e interpretación, entre los que destaca el de libertad civil, conforme al cual las leyes se presumen dispositivas y la renuncia a los derechos derivados de ellas será válida en tanto no contraríe el interés o el orden público ni perjudique a terceros, junto a la peculiar concepción de la propiedad en el ámbito de las instituciones forales, con reflejo en el ámbito sucesorio y en el denominado patrimonio familiar. Se preservan las diversas formas de propiedad comunal, familiar y social en la línea de la tradición histórica.

Todo el elenco de pronunciamientos del TC que posteriormente serán analizados no han llegado a resolver una cuestión troncal o clave desde la perspectiva de la nueva normativa aprobada por el legislador vasco y que subyace tras la redacción de varios de los preceptos de la nueva Ley 5/2015, de 25 de junio, de Derecho civil vasco ${ }^{8}$ (en adelante, Ley 5/2015), concretada en dilucidar si el alcance material de la competencia exclusiva conferida al Estado para dictar normas para resolver los conflictos de leyes abarca igualmente o no aquellas normas orientadas a resolver los conflictos de naturaleza interlocal o intercomarcal (aquellos que surgen entre subordenamientos de ámbito

\footnotetext{
7 BOE núm. 39, de 15 de febrero de 2012.

8 BOE núm. 176, de 24 de julio de 2015.
} 
local o comarcal pertenecientes a una misma CA, como ocurre en el caso del País Vasco). No hay una categoría homogénea de este tipo de conflictos interlocales, cada CA donde tal pluralidad interna se externaliza presenta a su vez sus propias particularidades, y solo desde una actuación normativa autonómica podrá atenderse a tal atomizada heterogeneidad de supuestos conflictuales interlocales.

La auténtica piedra angular (que, tal y como luego analizaremos, ha sido muy cuestionada doctrinalmente) sobre la que se construye el desarrollo orgánico del renovado Derecho civil vasco viene asentada en el reconocimiento legislativo de la existencia de una vecindad civil vasca. Es un factor troncal o esencial para el futuro del ordenamiento civil vasco porque permite sentar la base conflictual, respetuosa por vía interpretativa con el diseño competencial fijado en el llamado bloque de constitucionalidad, integrado por los arts. 149.18 de la CE y 10.5 del EAPV y diseñar, así, un hilo conductor del mismo común para los tres Territorios Históricos que integran la CA Vasca.

Cabe anticipar que solo si se admite que, en atención al ámbito interlocal, y en el marco o contexto territorial interno en que se sitúan los conflictos que la norma pretende resolver (en una proyección ad intra del sistema), la CA del País Vasco tiene competencia para dar respuesta legislativa a los mismos cabrá aceptar desde un punto de vista dogmático la regulación contenida en la nueva ley, que en este extremo aparece como la necesaria respuesta a una laguna del sistema español de Derecho interregional y a una necesidad sentida de modo acuciante en el ámbito del País Vasco, al estimarse que de otro modo se vaciarían de contenido o se desnaturalicen tales instituciones forales.

La CE constituye la norma base sobre la que pivota este nivel de nuestro ordenamiento jurídico que atiende a supuestos del tráfico jurídico interregional e interlocal y cuya delimitación por razón de la materia refleja un ámbito ciertamente focalizado en sectores específicos como el Derecho de familia (sucesiones y matrimonio) en relación a la determinación de la ley aplicable, algunas cuestiones de Derecho patrimonial y al Derecho público económico.

A su vez, la influencia del subsistema europeo, fortalecido por el Tratado de Lisboa ${ }^{9}$, se proyecta y adquiere especial transcendencia al expandir su ámbito de actuación material al ámbito central de las instituciones forales que coexisten en nuestro sistema de Derecho interregional.

En la actualidad, la frecuencia con que se presentan relaciones jurídicas que conectan dos o más ordenamientos jurídicos diferentes que ofrecen respuestas contradictorias o divergentes determina la razón de ser del DIPr. La compleja división política y jurídica del mundo y la proliferación de las relaciones privadas que pueden enmarcarse en un contexto de tráfico externo

\footnotetext{
9 Puede verse en este aspecto, Álvarez Rubio, J. J., «La incidencia del Tratado de Ámsterdam en el sistema español de Derecho interregional», Anales de la Facultad de Derecho, noviembre de 2001, núm. 18, pp. 65-78.
} 
debido a la incorporación de elementos de internacionalidad o de heterogeneidad plantean problemas concretos a los que el DIPr pretende ofrecer respuesta ${ }^{10}$.

En efecto, la existencia de dicho elemento de internacionalidad o de heterogeneidad debe interpretarse en un sentido amplio que permita englobar dentro de tal concepción toda aquella situación afectada por la coexistencia, también dentro de un mismo Estado, de diversos ordenamientos jurídicos. Por ello, resulta especialmente llamativa la desatención o el olvido que el legislador español muestra respecto a esta controvertida cuestión, que emerge de forma creciente en el panorama jurisprudencial de nuestros tribunales.

La pluralidad interna también es objeto de creciente atención y regulación normativa en el plano europeo y en el convencional/internacional. Carece de toda lógica que nuestro legislador español desatienda tal sector ${ }^{11} \mathrm{o}$ que reaccione de forma inconexa mediante puntuales reformas de preceptos que materializan también para la dimensión interna del sistema la incorporación por referencia de soluciones previstas en convenios internacionales, como la operada en relación a los arts. 9.4, 9.6 y 9.7 del CC, modificados por la Ley 26/2015, de 28 de julio, de modificación del sistema de protección a la infancia y a la adolescencia ${ }^{12}$.

\subsection{Bases competenciales y dimensión histórica}

Teniendo presente la peculiar estructura territorial, normativa y orgánica del País Vasco y la diversidad jurídica interna que le es propia, es preciso reflexionar sobre la principal aportación de la nueva ley, al lograr sentar las bases para la elaboración de un auténtico sistema normativo de Derecho civil vasco y combinar las particularidades de cada uno de sus Territorios Históricos con la necesaria extrapolación a todo el País Vasco de ciertas instituciones privadas que vertebren el desarrollo futuro del mismo ${ }^{13}$.

10 Sobre la distinción entre las situaciones internas o jurídicamente homogéneas y situaciones heterogéneas jurídicamente o del tráfico externo, véase GonZález Campos, J. D., Derecho Internacional Privado. Introducción, Madrid, Universidad Autónoma (Xerocopia), 1984, p. 11.

11 Sobre el particular, véase PARRA Rodríguez, C., «La revisión del Derecho interregional español: un análisis desde los principios generales del Derecho que inspiran la reforma», en ForNER I DELAYGUA, J. J., González Beilfuss, C. y Viñas Farré, R. (coords.), Entre Bruselas y La Haya. Estudios sobre la unificación internacional y regional del Derecho Internacional Privado. Liber Amicorum Alegría Borrás, Madrid, Marcial Pons, 2013, p. 655, aludiendo a que la solución normativa vigente debe ser modificada para adaptarse a las nuevas necesidades presentes en la sociedad plurilegislativa española.

12 BOE núm. 180, de 29 de julio de 2015, y en cuya exposición de motivos se subraya que se reforman las normas de DIPr, en concreto los apartados 4, 6 y 7 del art. 9, «normas de conflicto relativas a la ley aplicable a la filiación, a la protección de menores y mayores y a las obligaciones de alimentos. Estas modificaciones responden, por un lado, a la incorporación de normas comunitarias o internacionales y adaptaciones terminológicas a las mismas y, por otro, a mejoras técnicas en la determinación de los supuestos de hecho o de los puntos de conexión y su precisión temporal».

13 Sobre este particular, véase Álvarez Rubio, J. J., «El nuevo Derecho privado europeo y sus repercusiones en el Derecho Civil Vasco", Derecho Civil Vasco del siglo XXI: de la Ley de 2015 a sus desarrollos futuros, Bilbao, Parlamento Vasco, 2016, pp. 167-185. 
Es cierta la reflexión histórica de que todos los Derechos forales se formaron en un mundo de predominio rural pero ello no ha impedido, por ejemplo a catalanes y aragoneses, elaborar y diseñar amplios cuerpos de leyes que se aplican a todos sus habitantes. Para el logro de tal fin era preciso dotar de contenido social a las instituciones forales, convertir sus costumbres y principios en un instrumento útil al servicio de los destinatarios de las normas, mantener una coherencia frente a la trayectoria histórico-normativa ya superada e impulsarla hacia el futuro, y difuminar sin eliminar sus elementos específicos esos obstáculos que impedían concebir unitariamente unos y otros ordenamientos (el vizcaíno, el alavés y el guipuzcoano).

Así se logra la necesaria síntesis cultural y el germen de unos cánones hermenéuticos propios que garanticen la adecuación de nuestras instituciones a los tiempos actuales. Y en este ámbito el contenido social de la reforma emprendida con la nueva Ley 5/2015 no debe pasar desapercibido.

Una breve reflexión sobre las raíces históricas del Derecho civil vasco permite indagar en el sentido inspirador del mismo. La propia exposición de motivos de la ahora derogada Ley vasca 3/1992 ya destacaba la arcaica formulación que caracterizaba al Derecho civil foral y su necesaria actualización, que no debía limitarse a un mero trabajo de recopilación sino orientarse a acomodar el ordenamiento foral a las técnicas y necesidades de la sociedad actual, para dar forma nueva y adaptar al mundo de hoy el viejo Derecho foral, que en Vizcaya y Álava ha sido básicamente Derecho escrito y en Guipúzcoa Derecho consuetudinario.

Como ya ha sido indicado, la CE es el primer elemento normativo a considerar en el sistema español de Derecho interregional. La relevancia de los preceptos constitucionales en la configuración del sistema español de Derecho internacional privado viene advertida por su primacía jerárquica y operatividad. Téngase en cuenta que, por un lado, despliega plenos efectos en relación a la delimitación y distribución competencial entre el Estado y las CCAA en materia de legislación civil y, por otro, consagra los valores jurídicos que componen las normas y el contenido del sistema español de DIPr ${ }^{14}$.

El art. 149.1.8 de la CE garantiza por un lado la diversidad de Derechos civiles forales o especiales existentes en nuestro ordenamiento jurídico y delimita por otro los ámbitos de la competencia normativa de las CCAA y del Estado. En efecto, la cláusula contenida en el citado precepto constitucional viene a garantizar la foralidad civil mediante la autonomía política de las CCAA.

En este aspecto, puede observarse la interpretación realizada por el Tribunal Constitucional en su Sentencia 88/1993, de 12 de marzo ${ }^{15}$, que en su FJ 1.b), párr. $3 .^{\circ}$ vino a establecer dicha garantía en los siguientes términos:

14 Álvarez Rubio, J. J., "La necesaria reforma del sistema español de Derecho interregional», Cursos de Derecho Internacional y Relaciones Internacionales de Vitoria-Gasteiz, Vitoria-Gasteiz, Servicio de Publicaciones de la Universidad del País Vasco, 1997, pp. 289 y ss.

15 STC 88/1993, de 12 de marzo. 
«El citado precepto constitucional, tras atribuir al Estado competencia exclusiva sobre la "legislación civil", introduce una garantía de la foralidad civil a través de la autonomía política, garantía que no se cifra en la intangibilidad o supralegalidad de los Derechos civiles especiales o forales, sino en la previsión de que los Estatutos de las Comunidades Autónomas en cuyo territorio aquellos rigieran a la entrada en vigor de la Constitución puedan atribuir a dichas Comunidades competencia para su conservación, modificación y desarrollo».

En idénticos términos se posiciona el propio TC en su STC 156/1993, de 6 de mayo, al recoger en su FJ 1.a) que:

«El art. 149.1.8 de la Constitución, tras atribuir al Estado competencia exclusiva sobre la "legislación civil", introduce una garantía de la foralidad civil a través de la autonomía política, garantía que no se cifra en la intangibilidad de los Derechos civiles especiales o forales, sino en la previsión de que los Estatutos de las Comunidades Autónomas en cuyo territorio aquellos rigieran a la entrada en vigor de la Constitución puedan atribuir a dichas Comunidades competencia para su conservación, modificación y desarrollo».

Tal precepto constitucional ha dado lugar a divergentes interpretaciones doctrinales en relación a su calificación como norma compleja compuesta por una regla general, una excepción a dicha regla general y, finalmente, algunas excepciones de la excepción, complejidad que ha demandado una interpretación y concreción exhaustiva sobre términos tales como "allí donde existan» en referencia a los Derechos civiles forales o especiales ${ }^{16}$, el alcance de la noción desarrollo de tales Derechos ${ }^{17}$ y la posición de paridad o igualdad entre los Derechos civiles forales, y entre estos y el Derecho común ${ }^{18}$.

Las distintas estructuras, dimensiones o niveles en los que se articula el sistema español de DIPr requiere de los diferentes legisladores (autonómico y estatal) un grado de entendimiento que permita articular, debido a la existencia de conflictos que representan realidades diferenciadas (conflictos internos o interregionales, conflictos intraeuropeos y conflictos extraeuropeos), una adecuada y coherente respuesta jurídica ${ }^{19}$.

16 Sobre la interpretación de dicho término, entre otras, STC 121/1992, de 28 de septiembre, que viene a recoger en su FJ 1 que: «[...] El amplio enunciado de esta última salvedad ("Derechos civiles forales o especiales") permite entender que su remisión alcanza no solo a aquellos Derechos civiles especiales que habían sido objeto de compilación al tiempo de la entrada en vigor de la Constitución, sino también a normas civiles de ámbito regional o local y de formación consuetudinaria preexistentes a la Constitución $[\ldots]$ ».

17 STC 88/1993, de 12 de marzo.

18 STC 226/1993, de 8 de julio, FJ 2, conforme al cual [...] «la Constitución —su art. 149.1.8, específicamente- viene solo a posibilitar una posición de paridad, si así quiere decirse, entre los Derechos especiales o forales, y entre ellos y el Derecho civil general o común, por vía de la atribución en exclusiva al Estado de la competencia sobre las "normas para resolver los conflictos de leyes", competencia que en principio asegura —como hemos dicho en la reciente STC 156/1993 — "un igual ámbito de aplicación de todos los ordenamientos civiles" (FJ 3). Tan solo en estos términos, y con las reservas dichas y las salvedades que se harán, cabría hablar de paridad entre ordenamientos civiles, paridad resultante, en definitiva, de la uniformidad de régimen en materia de Derecho interregional privado que la Constitución inequívocamente dispuso».

19 Véase, entre otros, IRIARTE ÁNGEL, J. L., «La armonización del Derecho internacional privado por la Unión Europea», Jado: Boletín de la Academia Vasca del Derecho, 2006, núm. 9, pp. 47-73. 
Se trata de una dualidad que dificulta en cierta medida una convivencia armoniosa entre ambos bloques normativos, sobre todo teniendo en cuenta que la doctrina viene advirtiendo desde hace varios años que la respuesta que ofrece nuestro sistema para solucionar conflictos de leyes, recogido en el capítulo IV del Título Preliminar del CC, parece haberse quedado anticuada en comparación con las novedosas técnicas y soluciones que ofrece un Derecho europeo que responde a criterios de especialización por razón de la materia ${ }^{20}$.

Nuestro sistema interno de solución de conflictos, que carece de una ley especial de Derecho interregional, pivota en torno al citado capítulo IV y los arts. 14.1 y 16.1 del CC cuyas líneas básicas se estructuran mayoritariamente sobre el principio de remisión a las normas de DIPr y la determinación de la vecindad civil como punto de conexión y criterio de sujeción personal a los diferentes ordenamientos jurídicos civiles.

En relación a lo apuntado, el proceso de actualización y desarrollo del Derecho civil vasco tiene su anclaje competencial en el tenor de los arts. 149.1.8 de la CE y 10.5 del EAPV, que reservan a la CA del País Vasco la competencia legislativa para la conservación, modificación y desarrollo del Derecho civil foral. No cabe obviar que el propio precepto constitucional reserva la competencia exclusiva del Estado en materia de «normas para resolver los conflictos de leyes», en clara referencia a las normas propias de nuestra disciplina de DIPr, dirigidas a la resolución de conflictos tanto internacionales como interregionales.

En efecto, el precepto constitucional garantiza por un lado el pluralismo de Derechos civiles forales o especiales y establece por otro los ámbitos de competencia legislativas de las CCAA y del Estado, y opta por un sistema uniforme de Derecho civil interregional ${ }^{21}$.

En este sentido, y sobre la calificación como uniforme del sistema de Derecho civil interregional, puede observarse la interpretación realizada por el Tribunal Constitucional en su Sentencia 156/1993, de 6 de mayo, conforme a lo señalado en su FJ 3, al indicar que:

«Hemos de partir de la firme premisa de que la Constitución reserva a la exclusiva competencia del Estado la adopción de las "normas para resolver los conflictos de leyes" [...] atribución competencial esta cuyos contornos o límites no es preciso definir ahora de manera acabada, porque no hay duda alguna de que se integra en todo caso en ella la adopción de las normas de conflicto y la definición de cada uno de sus elementos, entre los que se cuenta, y con la mayor relevancia, la determinación de los puntos de conexión que lleven a la aplicación, en supuestos de tráfico jurídico interregional, de uno de los ordenamientos civiles que coexisten en España. La Norma Fundamental —siguiendo en esto el

\footnotetext{
20 Sobre este particular, véase IRIARTE ÁNGEL, J. L., "Ámbito material y personal y normas conflictuales», Derecho Civil Vasco del siglo XXI: de la Ley de 2015 a sus desarrollos futuros, Bilbao, Parlamento Vasco, 2016, pp. 135-161.

21 Puede verse en este aspecto a IRIARTE Ángel, J. L., "Conflictos de leyes internos. Notas fundamentales de la situación actual», Jado: Boletín de la Academia Vasca del Derecho, 18 de diciembre de 2009, pp. 55-93.
} 
precedente del art. $15.1 .^{\circ}$ de la Constitución republicana- optó, inequívocamente, por un sistema estatal y, por tanto, uniforme de Derecho civil interregional y excluyó, en la misma medida, que pudieran las Comunidades Autónomas establecer regímenes peculiares para la resolución de los conflictos de leyes, ya por la vía de articular puntos de conexión diversos a los dispuestos en la legislación general ya, en otra hipótesis, por medio de la redefinición, alteración o manipulación de tales puntos de conexión. Esta es, en definitiva, una materia enteramente sustraída por el art. 149.1.8..$^{\circ}$ a la acción normativa de las Comunidades Autónomas y atribuida "en todo caso" a la legislación del Estado».

Este proceso debe ejecutarse sin obviar el novedoso Derecho europeo aplicable a los conflictos de leyes internacionales, para lo que será necesario, conscientes de la competencia exclusiva del legislador estatal en materia de normas para resolver los conflictos de leyes, que las CCAA como el País Vasco con Derechos civiles forales o especiales alienten al legislador estatal a mantener como referencia normativa el Derecho europeo ${ }^{22}$.

\subsection{Conflictos de leyes internos en el ámbito del País Vasco}

\subsubsection{Precedentes normativos}

El proceso de actualización y desarrollo del Derecho civil vasco tiene su anclaje competencial en el tenor de los arts. 149.1.8 de la CE y 10.5 del EAPV que reconocen al País Vasco la competencia legislativa para la conservación, modificación y desarrollo del Derecho civil foral o especial.

Teniendo presente la peculiar estructura territorial del País Vasco ${ }^{23}$ y la diversidad jurídica interna que le es propia, la nueva Ley 5/2015 sienta las bases sobre las cuales va a ser posible elaborar un auténtico sistema normativo de Derecho civil vasco que logre combinar las particularidades de cada uno de sus Territorios Históricos con la necesaria extrapolación a todo el País Vasco de cierta regulación normativa material que vertebre el desarrollo futuro del mismo.

El recordado maestro y precursor de los estudios vinculados al Derecho civil vasco, Adrián Celaya ${ }^{24}$ planteó con sobriedad y claridad los problemas a los que debería enfrentarse el legislador vasco de cara a la futura revisión de la Ley 3/1992, partiendo de ciertos datos históricos esenciales: el País Vasco era, en el orden civil, un conjunto de ordenamientos encontrados, un sistema

${ }^{22}$ En relación a esta interesante reflexión, entre otros puede verse el estudio del profesor ÁLVAREZ GonZÁlEZ, S., "Derecho internacional privado europeo, plurilegislación civil española y Derecho interregional (o ¿para quién legisla el legislador autonómico de Derecho civil?)», Dereito, vol. 15, 2006, núm. 1, pp. 264-285.

${ }_{23}$ Entre los numerosos estudios doctrinales realizados sobre tal vertiente cabe citar los trabajos de Fernández, T. R., Los Derechos Históricos de los Territorios Forales, Madrid, 1985, y el realizado por Lojendio, I. M., La Disposición Adicional Primera de la Constitución Española, Bilbao, 1988.

${ }^{24}$ En su ponencia sobre «Los conflictos de leyes y el futuro del Derecho civil vasco», presentada en las Jornadas de Estudio sobre los conflictos de leyes en el desarrollo del Derecho civil vasco, celebradas en Bilbao los días 25, 26 y 27 de noviembre de 1998. 
invertebrado. Por ello, la vertebración del Derecho civil foral vasco requería un esfuerzo de unificación mediante unas instituciones comunes y unas soluciones que introdujeran cauces de racionalidad para la resolución de los problemas conflictuales internos.

Mejorando los precedentes de la Ley 3/1992 (arts. 5 a 11, 14 y 16, 131, 148 y149), los arts. 8 a 11 de la nueva Ley 5/2015 devienen claves, al establecer su ámbito territorial y personal y fijar unas pautas técnico-normativas que permitan superar los conflictos interterritoriales derivados de la acusada pluralidad legislativa interna, además de delimitar el ámbito territorial de vigencia de sus disposiciones, al disponer en su art. 8 que este se extiende a todo el País Vasco, "salvo en aquellos preceptos en que expresamente se declare su vigencia en un territorio concreto». Cabe defender que esta redacción respeta y tiene presente la interpretación sentada por el TC respecto a la expresión «allí donde existan» empleada por el citado art. 149.1.8 CE.

Tal y como subraya su propia exposición de motivos, el nuevo texto pretende tener vigencia en toda la CA Vasca. Sus disposiciones han de ser aplicadas en todo el territorio porque, aunque es cierto que históricamente siguieron Álava, Guipúzcoa y Vizcaya distintos caminos, son escasas, y en muchos casos más formales que materiales, las diferencias en el amplio campo de la costumbre foral.

La necesidad de delimitar el ámbito de vigencia, es decir, el territorio en que rige una norma autonómica no debe considerarse contrario al entramado competencial sentado en la $\mathrm{CE}$ : dicho territorio será el de la propia $\mathrm{CA}$, en cuanto límite máximo, pero cabe que tal legislación civil foral no se aplique en todo su territorio. Por ello, debe admitirse la competencia para fijar tal ámbito.

La reserva competencial estatal para dictar reglas de resolución de los conflictos de leyes interregionales deriva de la necesidad de garantizar una aplicación armónica, uniforme e igualitaria de los distintos Derechos civiles que coexisten en España y la comprensión de tal reserva debe entenderse en dicho contexto. ¿Qué alcance interpretativo debe darse a tal competencia exclusiva estatal? El criterio de unidad competencial a la hora de abordar posibles extralimitaciones competenciales por parte de los respectivos legisladores autonómicos ha sido ya abordado en numerosas ocasiones por parte del TC, que posteriormente serán estudiadas.

La última de estas decisiones del TC, de fecha 13 de abril de $2013^{25}$ ha sido ya analizado por la doctrina ${ }^{26}$ y parece zanjar la polémica interpretativa surgida en torno a la inclusión o no de las denominadas normas de extensión o de-

25 STC 93/2013, de 23 de mayo.

26 Zabalo Escudero, M. E., «El nuevo sistema de los conflictos de leyes internos e internacionales: conexiones y divergencias», Bitácora Millennium DIPr, marzo de 2016, pp. 56 y ss.; véase igualmente IRIARTE ÁNGEL, J. L., "Parejas de hecho, Constitución y conflictos de leyes internos. Reflexiones acerca de la sentencia del tribunal constitucional de 23 de abril de 2013», Academia Vasca de Derecho, Boletín $J A D O$, Bilbao, junio de 2013, núm. 24, pp. 169-183. 
limitadoras del ámbito de aplicación dentro del concepto empleado en el texto Constitucional «normas para resolver los conflictos de leyes», al señalar que:

«Conforme a la doctrina expuesta la adopción de normas unilaterales o de extensión delimitadoras de los respectivos ámbitos de aplicación espacial y personal de la norma en tanto que técnica de solución de conflictos de leyes es, por tanto, una tarea que, en principio, resulta vedad a la actuación del legislador autonómico».

La cuestión que sigue quedando abierta tras este pronunciamiento del TC y que plantea la nueva Ley 5/2015 de Derecho civil vasco radica en si, conforme al tenor competencial atribuido al Parlamento vasco por el art. 10.5 EAPV, es factible constitucionalmente o no dictar normas de resolución de conflictos de leyes interlocales que subsisten en el seno de su territorio autonómico, junto al hecho de reconocer la existencia de una vecindad civil vasca, cuestiones ambas que serán abordadas a continuación.

\subsubsection{Técnica normativa empleada en la Ley 5/2015}

En atención al grado de uniformidad de sus normas los diferentes ordenamientos estatales pueden ser encuadrados en dos grandes grupos: simples o unitarios (que poseen un único sistema de fuentes de producción jurídica y una sola organización judicial) y complejos, caracterizados por la coexistencia dentro del mismo territorio estatal de diversos sistemas jurídicos que poseen su propio ámbito de vigencia, espacial o temporal ${ }^{27}$.

La pluralidad legislativa se produce en el seno de los denominados ordenamientos jurídicos complejos al coexistir sistemas jurídicos diversos dentro de un mismo sistema u ordenamiento estatal. Este pluralismo jurídico interno puede revestir diferentes modalidades en atención a la configuración política y jurídica sobre la que se vertebre cada Estado. Nuestro sistema jurídico se ubica en el grupo de estos ordenamientos complejos o pluralistas, caracterizado por la presencia de conflictos internos de carácter interterritorial, resultantes de ordenamientos que poseen un determinado ámbito de vigencia espacial.

Junto a la vertiente material o sustantiva de las instituciones a desarrollar, es preciso desentrañar el sentido del art. 10.5 del EAPV y la extensión de la competencia del legislador vasco respecto a los calificados conflictos interlocales. Conforme al tenor del precepto, el País Vasco posee competencia exclusiva en materia de:

«Conservación, modificación y desarrollo del Derecho civil foral y especial, escrito o consuetudinario propio de los Territorios Históricos que integran el País Vasco y la fijación del ámbito territorial de su vigencia».

27 Sobre las diferentes causas que generan el fenómeno de Estados plurilegislativos, véase BoRRÁs, A., «Les ordres plurilégislatifs dans le Droit international privé actuel», R. des C., 1994, t. 249, pp. 145-368. 
Los respectivos ordenamientos civiles poseen un ámbito de vigencia territorial determinado. El art. 10.5 del EAPV reconoce expresamente tal posibilidad de fijación espacial, en cuanto norma de delimitación del ámbito espacial de vigencia del Derecho civil del País Vasco, a fines internos del País Vasco y ante la pretensión de resolver los difíciles problemas que plantea la colisión de la legislación foral y la común, junto a la problemática derivada de la ausencia de aplicación uniforme de las normas de Derecho civil foral o especial dentro del territorio del propio País Vasco.

La ratio última que preside la tarea de reforma ahora emprendida con la Ley 5/2015 no es tanto redactar un Código, en el sentido de una ley que regule la totalidad de las instituciones conocidas en materia civil, sino tratar de equilibrar el respeto al reparto competencial establecido en el bloque de Constitucionalidad (arts. 149.1.8 de la CE y 10.5 del EAPV) con la necesidad de evitar que las instituciones forales queden anquilosadas, manteniéndolas vivas y permeables a cambios exigidos por el contexto social en el que han de desplegar toda su operatividad.

La premisa clave para alcanzar tal objetivo es superar el acusado provincianismo que siempre nos ha caracterizado en esta materia, y que permitió a Adrián Celaya acuñar la gráfica descripción de nuestro territorio como «Islas Vascongadas», en el sentido de la presencia de auténticos islotes jurídicos que impedían vertebrar unitaria y homogéneamente nuestro sistema civil foral.

Junto a la vertiente material o sustantiva de las instituciones a desarrollar, es preciso desentrañar el sentido del art. 10.5 del EAPV y la extensión de la competencia del legislador autonómico respecto a los calificados conflictos interlocales.

El debate se centra en determinar si tal precepto del Estatuto de Autonomía ampara o no la competencia del legislador vasco para establecer ciertas normas que desempeñan una función especial, dentro del Derecho interregional, incardinables dentro de una categoría de Derecho interlocal, y cómo proyectar la operatividad del art. 149.1.8 de la CE y sus límites sobre este ámbito.

Como premisa inexcusable debe tenerse presente que, aunque el precepto comentado sea la norma atributiva de competencia, tal disposición del EAPV debe ser interpretada de conformidad con la CE. La CE y los Estatutos de Autonomía (en adelante, EEAA) determinan la atribución de competencias «allí donde existan» tales Derechos civiles forales o especiales. En realidad, el precepto persigue justificar la competencia autonómica en el País Vasco para precisar la eficacia territorial del Derecho civil foral o especial, que se manifiesta de forma diversificada por razón del territorio, requiriendo por ello una regulación que aporte el necesario elemento de seguridad jurídica.

Tal problemática se apreciaba de forma especialmente intensa en Vizcaya, donde no ha existido una frontera nítida entre los ámbitos de aplicación de ambos ordenamientos civiles (foral y común). 
En definitiva, ante la difícil y variable determinación del ámbito territorial del Derecho civil foral en la CA del País Vasco, se ha de interpretar el precepto estatutario como comprensivo de la facultad autonómica para designar el territorio en que rige una norma foral, su ámbito de vigencia, dentro de los límites territoriales de la CA, pero siempre enmarcado en los contornos fijados por el art. 149.1.8 de la CE, por lo que no cabrá, en principio, una fijación en abstracto de dicho ámbito territorial. Debe considerarse, por tanto, que tal atribución competencial en orden a la delimitación del ámbito territorial de vigencia del Derecho civil foral del País Vasco es una necesidad que viene impuesta por los difusos contornos de las fronteras de aplicación de ambos ordenamientos civiles.

El conocimiento de esa realidad histórica es clave para interpretar y dotar de sentido a la disposición contenida en el art. 10.5 del EAPV, que integra junto al art. 149.1.8 de la CE el llamado bloque de la Constitucionalidad, y justifica que sea el Parlamento Vasco el encargado de aportar, atendiendo a sus raíces históricas, soluciones a esa situaciones mixtas, derivadas de la indicada diversidad legislativa.

Tal orientación, que resulta plenamente coherente con la pretensión de garantizar la plena efectividad de la «conservación, modificación y desarrollo» de tales Derechos civiles forales, y que resulta irreprochable en cuanto a su lógica interna, presenta, sin embargo, un difícil encaje desde una perspectiva exclusivamente formal del sistema, conforme a la doctrina sentada por el TC.

Solo si se interpreta que tal actuación del legislador autonómico no implica una fragmentación de este en tantos sistemas interregionales como Derechos civiles forales o especiales existen, podrá evitarse el reproche derivado de la distorsión que su proyección general sobre el sistema podría plantear, para atender a las circunstancias específicas reguladas y considerar así que la sede lógica para su regulación, con fundamento en las soluciones históricamente establecidas, radica en el propio Parlamento vasco.

Para dar respuesta a todo ello, el capítulo tercero del título preliminar de la nueva Ley 5/2015 aborda la siempre espinosa cuestión de los conflictos de leyes internos en el ámbito del País Vasco y de forma acertada huye de la tentación de dictar normas particulares en materia de conflictos, por lo que efectúa en su art. 9 una remisión general a las soluciones previstas en el CC, "a falta de normas especiales», y una reserva para el supuesto de la troncalidad, institución que ya fue tratada de forma diferenciada, desde el punto de vista conflictual, en el propio CC.

El tenor literal del precepto señala bajo el poco afortunado título de «normas de conflicto», que:

«1. Corresponde al Parlamento Vasco la delimitación del ámbito territorial de vigencia de la ley civil vasca y, en su caso, las normas de resolución de conflictos internos de leyes, en cuanto subsista dentro del territorio de la Comunidad Autónoma del País Vasco la pluralidad legislativa. 
2. A falta de normas especiales, los conflictos de leyes a los que dé lugar la coexistencia de varios ordenamientos jurídicos se resolverán de acuerdo con las normas de carácter general dictadas por el Estado, atendiendo a la naturaleza de las respectivas instituciones.

3. Los conflictos locales entre normas vigentes en algunos territorios, o entre dichas normas y las generales de la Comunidad Autónoma del País Vasco, se resolverán también por las disposiciones del Código Civil, sin perjuicio del principio de territorialidad en materia de bienes troncales».

De este modo, este art. 9 de la nueva Ley 5/2015 reconoce expresamente la existencia de un doble nivel de conflictos dentro del Derecho interregional, distinguiéndose entre los conflictos internos (derivados de la coexistencia de varios ordenamientos jurídico-civiles) y los denominados conflictos locales (producidos entre las normas internas vigentes en alguno de los Territorios Históricos, o entre dichas normas y las generales del propio País Vasco).

El objetivo es responder a la previsión del citado art. 10.5 del EAPV, en cuanto a la necesaria fijación del ámbito espacial del Derecho civil vasco, sin incorporar nuevos criterios de conexión ni contener una regulación ex novo de la vecindad civil, al establecer de forma expresa una remisión in toto al régimen regulador de la vecindad civil contenida en el CC.

$¿$ Existen argumentos para sostener de forma argumentada y fundada que las CCAA en las que pervive un pluralismo interno autonómico, como es el caso del País Vasco, tienen competencia para dictar las normas necesarias para resolver los conflictos de leyes intracomunitarios (o interlocales, como se prefiera) producidos dentro de los límites de su propio ámbito territorial ${ }^{28}$ ?

La argumentación fundamental en la que cabe sustentar la respuesta favorable o positiva a tal interpretación se asienta en la idea motor de que tales normas son imprescindibles o necesarias para la propia aplicación del Derecho civil foral y que presuponen el régimen común, es decir, no alteran, no interfieren y no generan un punto de conexión novedoso que altere tal exigencia de unidad de solución de los conflictos internos en el nivel interregional.

¿Respeta el nuevo art. 9 de la Ley 5/2015 el plano competencial previsto en el art. 149.1.8 de la CE? Cabe afirmar que sí, por los siguientes motivos: porque deriva de la competencia fijada en el propio bloque de constitucionalidad (art. 10.5 del EAPV) a favor del Parlamento Vasco para delimitar el ámbito territorial de vigencia de la ley civil vasca, porque dicho Parlamento tiene competencia para dictar las normas llamadas a resolver los conflictos interlocales que se susciten en el seno del País Vasco y porque los demás conflictos de leyes interregionales que pudieran existir se resolverán de acuerdo con las normas dictadas por el Estado.

${ }_{28}$ Cuestión que fue analizada y respondida de forma positiva, entre otros, por Delgado EchEVE-

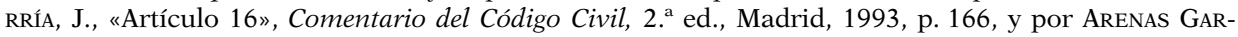
CÍA, R., «Derechos forales, Derechos locales y Derecho consuetudinario en España: origen histórico y determinación de su ámbito de vigencia territorial», R. J. de Asturias, 1997, pp. 110-111. 
Tal y como destacó el Dictamen del Consejo de Estado núm. 1537/92, relativo a la adecuación al orden de competencias derivado de la Constitución y del Estatuto de Autonomía del País Vasco de la Ley 3/1992, de 1 de julio, del Derecho civil foral ${ }^{29}$, el eventual desajuste con el sistema competencial previsto en la CE podría concretarse en la extensión de la competencia autonómica para la conservación, modificación y desarrollo de los Derechos forales o especiales «allí donde existan», que debe ceñirse al concreto ámbito territorial en que tuviese vigencia el Derecho foral en el momento de aprobarse la CE. En definitiva, solo admitiendo que la CA del País Vasco tiene competencia para fijar, dentro de su territorio, el límite espacial de vigencia del Derecho foral podrá desplegar todos sus efectos el último inciso del art. 10.5 del EAPV.

El conocimiento de esa realidad histórica es clave para interpretar y dotar de sentido a la disposición contenida en el art. 10.5 del EAPV, que integra junto al art. 149.1.8 de la CE el denominado bloque de Constitucionalidad y justifica que sea el Parlamento Vasco el encargado de aportar, atendiendo a sus raíces históricas, soluciones a esas situaciones mixtas, derivadas de la indicada diversidad legislativa interna.

En este ámbito, cobra especial interés la construcción dogmática elaborada por el Prof. Julio D. González Campos ${ }^{30}$, quien tras centrarse en una vertiente formal del sistema (extraída de la interpretación del tenor literal del texto Constitucional), consideró que no vulneraría el art. 149.1.8 de la CE el hecho de admitir que, siempre que la misma naturaleza de una institución foral lo justifique, y de acuerdo con la tradición histórica de ese ordenamiento, pueda el legislador de una CA determinar el ámbito de aplicación espacial del propio Derecho material, foral o especial, a la par que modifica o desarrolla este.

El señalado Dictamen del Consejo de Estado añadió así un escalón más al ámbito del Derecho interregional, y considera (pp. 56 y ss.) que las presunciones acerca de la vecindad civil establecidas en el precepto no se refieren a los conflictos interregionales, sino a los que puedan producirse «en el interior de la propia Comunidad Autónoma», dada la existencia de diversos regímenes de Derecho civil. Por ello, considera:

1. Que tales normas resultan necesarias para la aplicación del propio Derecho foral.

29 Consejo de Estado. Recopilación de doctrina legal, 1993, pp. 66-92.

30 González Campos, J. D., Derecho internacional privado I: Introducción, Madrid, 1984, pp. 171172. No obstante, y pese a que tal interpretación es defendible desde el objetivo o ratio de garantizar una adecuada convivencia entre ordenamientos, sobre todo cuando estemos ante normas destinadas a resolver conflictos interlocales que se materialicen y agoten sus efectos en el seno de una concreta CA, el propio profesor González Campos manifestó que el Tribunal Constitucional «...al afirmar que esta es, en definitiva, una materia enteramente sustraída por el artículo 149.1.8 CE a la acción normativa de las Comunidades Autónomas excluye la posibilidad, defendida por la doctrina, de que las Comunidades Autónomas, tras la Constitución, pudieran delimitar unilateralmente el ámbito de aplicación de algunas instituciones de su Derecho civil propio, como habían hecho algunas Compilaciones». GonzÁLEZ CAMpos, J. D., "Los conflictos internos en el sistema español de Derecho internacional privado», en PÉrez Vera. E. (dir.), Derecho internacional privado, vol. 1, Madrid, 1998, p. 71. 
2. Que presuponen el régimen general común, al no incorporar modificación alguna frente a lo dispuesto en la legislación civil general (argumento discutible, ya que una eventual modificación de la legislación general o común introduciría un nuevo elemento de complejidad en el reparto competencial).

La construcción realizada vendría a defender que, en realidad, la norma dictada por el legislador autonómico no pretende solucionar conflictos interregionales en sentido estricto sino los propios conflictos internos que en el seno de la CA del País vasco pudieran producirse ante la diversidad legislativa apuntada y con el sustrato histórico ya analizado. En efecto, desde un punto de vista dogmático podría optarse, bien por configurar una categoría de normas de Derecho interlocal, que se proyecta sobre el territorio de la CA, o en segundo lugar, y sin crear dicha categoría, estimar que tales normas vienen caracterizadas por contener una conexión implícita a través de una directa vinculación con el territorio interno de la CA, atendiendo a supuestos conflictivos localizados en el mismo.

$¿$ ¿Se trata de una norma material especial de Derecho interregional? ¿Salva tal calificación la Constitucionalidad de la norma? ¿Qué alcance interpretativo debe darse al confuso tenor del art. 149.1.8 de la CE, al aludir a normas para resolver los conflictos de leyes? ¿Dónde está el límite o umbral para una adecuada interpretación de la reserva estatal en tal materia? ¿Puede admitirse la Constitucionalidad de la norma alegando que su aplicación ha de producirse dentro del territorio de la CA y, por tanto, considerar que no se trata de una norma de resolución de los conflictos interregionales, sino de los propios conflictos que pudieran suscitarse por la diversidad de regímenes jurídicos civiles coexistentes en el País Vasco? La respuesta propuesta a dichos interrogantes conforme a los argumentos expuestos es afirmativa.

El debate doctrinal acerca del alcance de la regla del art. 149.1.8 de la CE y en particular, saber si tal competencia exclusiva puede verse mediatizada a través de una interpretación flexibilizadora de su tenor literal que evite la desnaturalización de las instituciones forales debe partir de los precedentes sentados por el TC.

Tal orientación fue confirmada en la STC 156/1993, de 6 de mayo, al subrayar en el FJ 3 que la Constitución ha optado por establecer un sistema estatal uniforme de Derecho civil interregional, al tratarse de una materia enteramente sustraída por el art. 149.1.8 de la CE a la acción normativa de las CCAA. En particular, el FJ 2.b) de la citada sentencia destaca expresamente que:

«La disposición impugnada afecta, sin duda, a la vecindad civil y al constituir esta, según se recordó, punto de conexión para la determinación del estatuto personal es claro que mediante aquella se viene a incidir sobre un aspecto nuclear del Derecho interregional, sector este del ordenamiento al que la norma Constitucional se refiere (junto al Derecho internacional privado) con la expresión "normas para resolver los conflictos de leyes"». 
Se excluye, en definitiva, toda posibilidad de fijación de regímenes autonómicos peculiares para la resolución de los conflictos de leyes, tal y como confirma la ya comentada STC 226/1993, de 8 de julio, al subrayar en su FJ 2 la uniformidad de régimen en materia de Derecho interregional, con el fin de asegurar un igual ámbito de aplicación de todos los ordenamientos civiles, y una posición de paridad o igualdad entre todos ellos, y reiterar (FJ 4), que:

«La Constitución optó, inequívocamente, por un sistema estatal y, por tanto, uniforme de Derecho civil interregional, de modo que es a las Cortes Generales a quien corresponde el establecimiento de las normas de conflicto para la resolución de supuestos de tráfico interregional y, antes aún, la definición y regulación, en general, de los puntos de conexión conforme a los cuales han de articularse aquellas reglas».

El tenor literal del art. 149.1.8 CE, al atribuir competencia exclusiva al Estado en la materia reseñada, plantea una nueva polémica sobre las técnicas de reglamentación que deben incardinarse en la expresión «normas para resolver los conflictos de leyes». En particular, el debate se plantea en torno a la extensión de la competencia autonómica para determinar el ámbito de vigencia espacial y personal de su Derecho civil foral, y la posibilidad o no de acogerse, para su fijación, a otras técnicas normativas diferentes de la norma de conflicto, estableciendo normas materiales especiales para el tráfico interregional.

De este modo, surgen orientaciones doctrinales que sostienen, en cuanto al alcance de la técnica normativa contemplada en el art. 149.1.8 CE, que esta es exclusivamente la norma de conflicto, de forma que las CCAA podrían reglamentar tal ámbito personal o territorial de su legislación foral o especial acudiendo a otras técnicas normativas o al menos sostener que no debe olvidarse el respeto a los principios que inspiran las instituciones reguladas en los diversas legislaciones forales o especiales, de forma que estas no queden desnaturalizadas.

En efecto, tal y como ha sido analizado, si el legislador autonómico careciera de competencia para legislar sobre tales conflictos internos, producidos en el seno de su territorio, no existiría vía alguna para tratar de remediar situaciones conflictivas derivadas de tal diversidad legislativa, y que históricamente han generado la necesidad de aportar una solución frente a la inseguridad jurídica generada.

Frente a tales construcciones doctrinales, el sistema español viene caracterizado, desde una perspectiva formal, y a través del tenor del art. 149.1.8 de la CE y la doctrina del TC como un sistema unitario de solución de los llamados conflictos de leyes, al haber optado por dejar en manos del Estado el establecimiento del llamado Derecho interregional, y evitar su fragmentación.

Sin embargo, y al margen de los ya comentados límites constitucionales a esa facultad estatal de configuración del sistema de forma uniforme, la exposición realizada sobre el alcance de los preceptos contenidos en la nueva Ley vasca 5/2015 plantea el interrogante acerca de si tal grado de uniformidad 
queda realmente afectado por la intervención del legislador autonómico en la resolución de conflictos puramente internos, que quedarían sin respuesta caso de no admitirse la misma.

Además, esta viene justificada por el análisis histórico realizado, que demuestra su origen y los intentos esbozados a lo largo de su evolución, dirigidos a eliminar o atenuar sus efectos sobre el Derecho civil foral.

\subsection{La vecindad civil vasca, piedra angular de la nueva ley}

La exposición de motivos de la Ley 5/2015 destaca que su innovación más importante se encuentra en la regulación de la vecindad civil vasca. Hasta ahora no existían sino las vecindades locales guipuzcoana, vizcaína y avalesa (dentro de Álava), y la nueva ley subraya que la existencia de una vecindad civil común, la vecindad vasca, es clave para poder atender a la resolución de los conflictos de leyes que se producen en el seno de la CA Vasca.

El art. 10 (complementado en su dimensión de aplicación temporal por la DA 7. a de la Ley), relativo a su ámbito de aplicación personal, delimita el ámbito subjetivo de aplicación de la norma, señalando que a los efectos de esta ley son vascos y están sometidos a la misma quienes tengan vecindad civil vasca. Tal vecindad civil vasca, así como la local, se adquiere, se conserva y se pierde conforme a las normas contenidas en el CC; tras esta doble clasificación (vecindad vasca y vecindad local) subyace la argumentación empleada por el Consejo de Estado en su anteriormente citado Dictamen de fecha 27 de mayo de 1993 (expediente núm. 1537/92), al distinguir diferentes niveles o escalones dentro de la problemática conflictual que afecta al País Vasco, situándola en el ámbito de los denominados conflictos interlocales.

A su vez, el art. 11 de la nueva Ley establece una doble presunción que afecta a la vecindad civil del otorgante y al régimen económico matrimonial o de la pareja de hecho, al señalar, en línea acorde con el anterior art. 14.2 de la Ley 3/1992, que en los instrumentos públicos se hará constar la vecindad civil vasca y la local del otorgante. El precepto articula tal presunción iuris tantum conforme a ciertos puntos de conexión (lugar de nacimiento, último domicilio común de los cónyuges y lugar de celebración del matrimonio o el de separación de bienes si se trata de parejas de hecho).

Junto a la pretensión de garantizar el desarrollo del Derecho civil foral y de alcanzar un necesario grado de seguridad jurídica en la aplicación de tales instituciones, debe recordarse que el citado Dictamen del Consejo de Estado consideró que las presunciones acerca de la vecindad civil establecidas en el precepto de la Ley vasca 3/1992 no se referían a los conflictos interregionales sino a los que pudieran producirse «en el interior de la propia Comunidad Autónoma», dada la coexistencia de diversos regímenes de Derecho civil.

Cabe defender que la ordenación contenida en esos arts. 8 a 11 de la nueva Ley 5/2015 se atiene al margen de actuación normativa previsto en el bloque 
de constitucionalidad. En particular, la regulación contenida ni altera la redacción contenida en el CC ni introduce una regulación que modifique los respectivos ámbitos de aplicación del Derecho civil común frente al Derecho civil vasco.

La CE y el EAPV determinan la atribución de competencias «allí donde existan» tales Derechos civiles forales o especiales. En realidad, el precepto persigue justificar la competencia autonómica en el País Vasco para precisar la eficacia territorial del Derecho civil foral o especial que se manifiesta de forma diversificada por razón del territorio, requiriendo, por ello, una regulación que aporte el necesario elemento de seguridad jurídica.

El antes citado Dictamen del Consejo de Estado núm. 1537/92 defendió la adecuación al orden competencial establecido en la CE a través de una construcción teórica que añadía un escalón más al ámbito del Derecho interregional, al referirse a los conflictos que puedan producirse «en el interior de la propia Comunidad Autónoma», dada la existencia de diversos regímenes de Derecho civil.

Por ello, consideró que tales normas resultan necesarias para la aplicación del propio Derecho foral y que presuponen el régimen general común, al no incorporar modificación alguna frente a lo dispuesto en la legislación civil general. La construcción realizada vendría a defender que, en realidad, la norma dictada por el legislador vasco no pretende solucionar conflictos interregionales en sentido estricto sino los propios conflictos internos que en el seno del País Vasco pudieran producirse ante la diversidad legislativa apuntada y con el sustrato histórico que posteriormente será analizado.

De esta forma, no puede hablarse de creación ex novo de una nueva vecindad civil (la vecindad civil vasca), sino que en realidad se positiviza el reconocimiento de la existencia de tal categoría como única vía conflictual que permita hacer realidad la aplicación de ciertas instituciones civiles propias del Derecho civil vasco a los tres Territorios Históricos, respetando las particularidades o especificidades de cada uno de ellos, pero a la vez dando plasmación normativa a una realidad subyacente históricamente y que por primera vez adquiere refrendo legal.

Ninguno de los preceptos contenidos en la nueva ley responde a una actitud caprichosa del legislador vasco, ya que detrás de cada particular regulación se aprecia la pretensión de asegurar, frente a la diversidad jurídica que caracteriza al País Vasco, una adecuada aplicación y salvaguarda de las instituciones forales. Desde un ángulo histórico cabe apreciar la voluntad del legislador autonómico de pretender adaptarse a unas circunstancias muy particulares que requieren respuestas normativas específicas.

Estas se articulan a través de normas que desempeñan una función especial, dentro del Derecho interregional, enmarcada en una subcategoría que cabe calificar como Derecho interlocal, en una vertiente ad intra del sistema, con la pretensión de responder a las peculiaridades derivadas de la parcelación del Fuero y la diversidad legislativa que caracteriza al Derecho civil 
vasco. Se trata, en definitiva, de unas normas (las contenidas en estos arts. 8 a 11 de la nueva Ley) adecuadas, convenientes e imprescindibles para la propia regulación sustantiva de las instituciones normativas civiles especiales vascas.

\section{EL ÁMBITO DEL DERECHO PÚBLICO AUTONÓMICO}

Junto a la dimensión tradicional de los conflictos internos planteados en el seno del sistema español derivada de la pluralidad de los Derechos civiles y la referencia a la vecindad civil como conexión para determinar la ley personal han surgido, fruto del desarrollo de las previsiones constitucionales y de los respectivos EEAA y en el marco de una estructura de Estado no uniforme, caracterizado por la atribución de poderes legislativos a las CCAA, numerosos problemas de delimitación del ámbito de vigencia de los diferentes ordenamientos, e incluso la presencia de conflictos de leyes internos en materias que trascienden a los ámbitos materiales tradicionales.

Este novedoso ámbito es consecuencia del ejercicio por parte de las CCAA de sus respectivas competencias exclusivas, conforme al reparto competencial diseñado en el llamado bloque de la constitucionalidad. Dicho pluralismo se manifiesta en sectores que, desde el punto de vista de la legislación emanada por los legisladores autonómicos respectivos, cabe calificar de públicos, ya que, como indicó la STC 264/93, de 22 de julio, tal regulación autonómica debe ceñirse «al ámbito de las relaciones jurídico-públicas, impidiendo o tutelando las prácticas lesivas de los intereses tutelados, definiendo las conductas exigibles en congruencia con tales intereses y estableciendo las sanciones administrativas pertinentes».

Esa nueva dimensión de los conflictos internos corresponde al llamado Derecho público económico y atiende como premisa básica al reparto o distribución competencial entre el Estado y las CCAA, articulado en el Título VIII de la CE, viene caracterizado por factores específicos como el recurso, dentro de las técnicas de reglamentación, a la unilateralidad como solución de base, y deberá atenderse a problemas derivados de las conexiones empleadas, bien por el legislador autonómico o por el estatal.

Las normas dictadas por las CCAA deben necesariamente determinar su ámbito de aplicación, ya que su ejercicio se concreta por referencia al territorio donde deben ser aplicadas.

Debe atenderse, por tanto, a las complejas relaciones entre los ordenamientos estatal y autonómicos en materia de Derecho público económico. Numerosas sentencias del TC destacan que en este ámbito material se produce un complejo entrecruzamiento de títulos competenciales, tanto estatales como autonómicos, como a continuación se analizará en estas reflexiones sobre la nueva dimensión de los conflictos internos dentro del sistema español de DIPr. 
Este novedoso ámbito fue analizado de forma tan pionera como brillante por el Prof. Julio D. González Campos ${ }^{31}$, y es consecuencia del ejercicio por parte de las CCAA de sus respectivas competencias exclusivas, conforme al reparto competencial diseñado en el llamado bloque de la constitucionalidad. Dicho pluralismo se manifiesta en sectores que, desde el punto de vista de la legislación emanada por los legisladores autonómicos respectivos, cabe calificar de públicos, ya que, como señaló la STC 264/93, de 22 de julio ${ }^{32}$, tal regulación autonómica debe ceñirse:

«Al ámbito de las relaciones jurídico públicas, impidiendo o tutelando las prácticas lesivas de los intereses tutelados, definiendo las conductas exigibles en congruencia con tales intereses y estableciendo las sanciones administrativas pertinentes».

Desde nuestra perspectiva de análisis, interesa especialmente aquella legislación autonómica que tiene incidencia en la actividad económica desarrollada por los particulares en el mercado nacional. Los dos presupuestos generales sobre los que se asienta esta nueva dimensión del Derecho público económico de las CCAA serían la unidad de mercado, consagrada en el art. 149.1.13 CE (al atribuir al Estado competencia exclusiva respecto a las bases y coordinación de la planificación general de la actividad económica) y el art. 38 (al reconocer la libertad de empresa en el marco de la economía de mercado, encomendando a los poderes públicos la protección y garantía de su ejercicio, de acuerdo con las exigencias de la economía general y, en su caso, de la planificación), junto al art. 139.1 CE, al establecer que:

«Todos los españoles tienen los mismos derechos y obligaciones en cualquier parte del territorio del Estado».

La propia Constitución establece en primer lugar el marco jurídico fundamental de la actividad económica, y fija ya ciertos objetivos básicos, concretados, como señaló la STC 1/1982, de 28 de enero ${ }^{33}$, en:

«La exigencia de que el orden económico nacional sea uno en todo el ámbito del Estado [...] unidad del orden económico nacional que es un presupuesto para que el reparto de competencias entre el Estado y las distintas CCAA no conduzca a resultados disfuncionales y desintegradores».

El logro de tal objetivo motiva así la atribución al Estado de la competencia exclusiva en relación al comercio exterior, el régimen aduanero y arancelario, el sistema monetario y la fijación de las bases de la ordenación del crédito, banca y seguros, así como (ex art. 149.1.13 de la CE), competencia para la ordenación general de la economía, y bases y coordinación de la planificación general de la actividad económica. Esta atribución competencial modulará o mediatizará el ejercicio por parte de las CCAA de competencias exclusivas en

31 González Campos, J. D., «El marco Constitucional de los conflictos internos en España», Europäischer Binnenmarkt IPR und Rechtsangleichung, C. F. Müller, pp. 7-34, en un estudio que aportó claves futuras para un necesario desarrollo doctrinal posterior sobre el particular.

32 Jurisprudencia Constitucional, 1993, t. XXXVI, pp. 1225 y ss.

33 Jurisprudencia Constitucional, 1982, t. III, pp. 1 y ss. 
materias, por ejemplo, de mercado interior, ya que el Estado posee, también con carácter exclusivo, competencia para fijar las bases o legislación básica en ese ámbito, que será aplicable en todo el territorio español.

El citado presupuesto de la unidad del orden económico se refuerza a través de otros derechos constitucionalmente establecidos: en primer lugar, la libertad de empresa, en el marco de la economía de mercado, previsto en el art. 38 de la CE, de forma que toda actuación del legislador autonómico deberá respetar su contenido esencial, al operar, como indicó la STC 37/1981, de 16 de noviembre ${ }^{34}$, en cuanto límite:

«Dentro del que han de moverse los poderes públicos al adoptar medidas que incidan sobre el sistema económico de nuestra sociedad».

En segundo lugar, el art. 139 de la CE (apdos. 1 y 2) reconoce la igualdad sustancial de la situación jurídica de todos los españoles en cuanto tales en todo el territorio nacional, y de la libre circulación de personas y bienes. Ello no exige una absoluta uniformidad en la actividad económica, sino que prohíbe que una legislación autonómica obstaculice la libertad económica o se impida el acceso al mercado en una parte del territorio nacional.

Un segundo elemento de análisis en esta novedosa dimensión de los conflictos internos ha de contemplar la territorialidad del Derecho autonómico, en cuanto factor del que pueden derivarse conflictos internos ${ }^{35}$, ya que dos legisladores autonómicos pueden, al regular una misma materia, establecer que tal ordenación se aplique bien a todos los que se hallan en el territorio, o solo a los que realizan ciertos actos en el mismo. Junto a ello, debe tenerse presente que, incluso determinando que tal legislación sea de aplicación exclusivamente territorial, podrá producir efectos indirectos fuera del territorio.

El análisis de la jurisprudencia del TC y en particular, las SSTC 48/1988, $86 / 1989,150 / 1990,72 / 1983,44 / 1984$ y 165/1985, conducen a la reflexión final de que existe un doble control de constitucionalidad de la norma o del acto autonómico, en el plano del ámbito espacial de aplicación y en el de su eficacia en el espacio. De este modo, las normas y actos autonómicos pueden suscitar conflictos de leyes en atención a la delimitación espacial de los supuestos contemplados por los diferentes legisladores, lo cual conduce directamente al examen de las conexiones utilizadas, para precisar su alcance ${ }^{36}$.

Pero también pone de relieve, en segundo término, que, aun no suscitándose ningún conflicto en esta primera dimensión, el acto o norma adoptada

34 Jurisprudencia Constitucional, 1981, t. II, pp. 293 y ss.

35 Como señaló González Campos, J. D., op. cit., nota 26, p. 20, de los distintos aspectos de la territorialidad, es el material el que importa en primer lugar, dado que el legislador autonómico, en relación con una determinada materia, ha de establecer el ámbito de aplicación espacial de la norma o el acto que dicta [...]; el legislador autonómico establece una delimitación del ámbito de aplicación de la norma o del acto en relación con el propio territorio y, lógicamente, ello implica que se han de producir unos efectos jurídicos directos ad intra. Pero aun circunscrito el ámbito de aplicación al propio territorio, es posible que también se produzcan ciertos efectos o consecuencias jurídicas de la norma o del acto autonómico ad extra, más allá del territorio de la Comunidad.

36 Sobre el particular, véase Álvarez RuBio, J. J., op. cit., nota 9, pp. 275-323. 
por la CA puede producir efectos fuera de su territorio y, de este modo, invadir la competencia del legislador estatal o la que corresponda a otros legisladores autonómicos.

Atendiendo a tales premisas, y respecto a la señalada eficacia extraterritorial de las normas y actos autonómicos, cabe citar la STC 37/1981, de 16 de noviembre ${ }^{37}$, en relación con la Ley del Parlamento Vasco 3/1981 sobre centros de contratación de transporte terrestre de mercancías, al cuestionarse la constitucionalidad de un precepto por el que se establecía que los centros de carga podían operar respecto a ofertas de transporte «con origen en Euskadi», y estimarse en el recurso que, para evitar efectos en otras CCAA, debería haberse limitado a ofertas de transporte con origen y destino en Euskadi.

El TC, tras reconocer la competencia de la CA en esta materia, y que tal atribución quedaba referida, salvo disposición expresa en contrario, al ámbito territorial del País Vasco, consideró que:

«Esta limitación territorial de la eficacia de normas y actos no puede significar en modo alguno que le esté vedado en uso de sus competencias propias, adoptar decisiones que puedan producir consecuencias de hecho en otros lugares del territorio nacional» [al estimar que de lo contrario, si se excluyera cualesquiera consecuencias más allá de sus límites territoriales], «equivaldría necesariamente a privarlas, pura y simplemente, de toda capacidad de actuación».

En todo caso, tal posibilidad de producir consecuencias fuera del territorio de la CA deberá ser apreciada en relación con el límite del art. 139.1 de la CE.

$\mathrm{El}$ análisis de la indicada jurisprudencia permite inferir que es necesario distinguir entre los conflictos generados entre legislación estatal/legislación autonómica y los derivados de divergencias de dos o más legisladores de las distintas CCAA, que al adoptar criterios de conexión de los supuestos con el territorio pueden determinar la presencia de un conflicto de leyes positivo o negativo, todavía no planteado de forma directa ante los órganos jurisdiccionales, pero que permiten sostener la necesidad de elaborar un sistema estatal de soluciones para tales conflictos de leyes en este segundo nivel.

El propio TC ha formulado una clara doctrina sobre la incidencia del principio de territorialidad y la obligada sujeción del ejercicio de sus respectivas competencias por parte del Estado y de las CCAA a ciertos principios constitucionales, y así, en Sentencias como la 37/1981 o la 48/1998, ha establecido que el ámbito de la competencia autonómica viene dado por el principio de territorialidad, sin perjuicio de las posibles consecuencias extraterritoriales que de facto pudieran derivarse de las decisiones adoptadas en el ejercicio de tales competencias autonómicas, así como de las excepciones que estatutariamente puedan preverse o resulten de las normas dictadas para resolver los conflictos de leyes.

Respecto a la eventual vulneración de principios constitucionalmente establecidos en relación a la unidad de mercado, que exige la libre circulación

37 Jurisprudencia Constitucional, 1981, t. II, pp. 293 y ss. 
de bienes, capitales y servicios por todo el territorio nacional y la igualdad de las condiciones básicas del ejercicio de la actividad económica, el TC ha reiterado que no debe confundirse unidad de mercado con uniformidad, ya que la propia configuración del Estado en distintas CCAA conlleva necesariamente una diversidad de regímenes jurídicos (STC 88/1996).

El TC soluciona esta aparente contradicción exigiendo la proporcionalidad del régimen jurídico establecido por una CA dentro del ámbito de su competencia con el fin perseguido, siempre que se respete la igualdad básica de todos los españoles. Y en la Sentencia de 12 de diciembre de 2007 reiteró que el principio de igualdad constitucionalmente proclamado no excluye la diversidad de posiciones jurídicas de las CCAA y que la igualdad de derechos y obligaciones de todos los españoles en cualquier punto del territorio nacional no puede ser entendida como rigurosa uniformidad del ordenamiento.

En definitiva, se reitera que el principio de igualdad sustancial no puede confundirse con un principio de uniformidad. No existe homogeneidad absoluta de los derechos de los ciudadanos en todo el territorio nacional. Expresamente señala el TC que «tal principio de igualdad no puede ser entendido en modo alguno como una rigurosa y monolítica uniformidad del ordenamiento de la que resulte que, en igualdad de circunstancias, en cualquier parte del territorio nacional se tiene los mismos derechos y obligaciones. Esto no ha sido nunca así entre nosotros en el ámbito del Derecho privado».

Por tanto, y esta es la clave, el principio constitucional de igualdad no impone que todas las CCAA ostenten las mismas competencias, ni menos aún, que tengan que ejercerlas de una manera o con un contenido y unos resultados idénticos o semejantes. Los ciudadanos residentes en los distintos territorios autonómicos pueden estar sometidos a regímenes jurídicos diferenciados en las áreas materiales correspondientes a dichas competencias, y consecuentemente tener diferentes derechos en esas áreas. La Constitución no exige ni proclama la uniformidad absoluta respecto de los derechos constitucionales.

\section{CONSIDERACIONES FINALES}

Aquellos conflictos normativos que deriven de la concurrencia de distintas peculiaridades normativas civiles dentro del País Vasco pueden y deben recibir respuestas normativas elaboradas por el respectivo legislador vasco, introduciéndose así una coordinación adecuada respecto a la competencia estatal en relación a este tipo particular de conflictos de leyes interlocales.

La auténtica piedra angular sobre la que construir el desarrollo orgánico de nuestro Derecho civil vasco viene asentada sobre el reconocimiento legislativo de la existencia de una vecindad civil vasca. Y es un factor troncal o esencial para el futuro de nuestro ordenamiento civil propio porque permite sentar la base conflictual. 
Solo si se admite que, en atención al ámbito interlocal, y en el seno del ámbito territorial interno del País Vasco en que se sitúan los conflictos que la norma pretende resolver (en una proyección ad intra del sistema), la CA tiene competencia para dar respuesta legislativa a los mismos cabrá aceptar la regulación contenida en la nueva ley, que en este ámbito normativo material y conflictual representa la necesaria respuesta a una laguna del sistema interno español de Derecho interregional y a una necesidad sentida de modo acuciante en el ámbito del País Vasco, al estimarse que de otro modo se vaciarían de contenido tales instituciones forales y se imposibilitaría su crecimiento orgánico como ordenamiento jurídico.

El debate troncal o principal de estas reflexiones reside en analizar cómo responder a la particularidad, no exclusiva o privativa de él pero sí especialmente agudizativa que caracteriza al Derecho civil vasco, concretado en la concurrencia de diversos subordenamientos locales o comarcales dentro del mismo ámbito territorial de la CA. Conforme a los argumentos expuestos, cabe interpretar el alcance de la competencia estatal prevista en el art. 149.1.8 $\mathrm{CE}$ en el sentido de que las CCAA en las que concurra tal singular circunstancia tiene competencia para poder dictar normas para resolver los conflictos normativos interlocales.

En particular, la previsión específica y única del art. 10.5 EAPV, que forma parte del bloque de constitucionalidad, ampara o da cobertura a esta segunda posible vía de interpretación, posibilitando que la CA del País Vasco tenga competencia para aprobar normas que pretendan resolver los conflictos de leyes intracomunitarios que se materializan dentro de ella.

Es ineludible abordar desde la dimensión y competencia del legislador estatal la reforma y modernización del sistema español de conflictos internos. Tal sistema requiere de una profunda renovación que permita superar las anacrónicas respuestas de un sistema de conflicto de leyes interno que queda en la actualidad condicionado por el proceso de europeización del Derecho internacional privado iniciado con el Tratado de Ámsterdam y consolidado y reforzado tras la entrada en vigor del Tratado de Lisboa.

\section{RESUMEN}

UNA RENOVADA DIMENSIÓN DE LOS CONFLICTOS INTERNOS: LA LEY 5/2015 DE DERECHO CIVIL VASCO Y LA INTERACCIÓN ENTRE BLOQUES NORMATIVOS

La nueva normativa civil vasca abre de nuevo el debate doctrinal acerca de la necesidad de que el inexistente sistema español de Derecho interregional sea objeto de atención por parte del legislador estatal para poder dar respuesta a los conflictos derivados de la interacción entre bloques normativos. Nuestro sistema jurídico estatal se ubica en el grupo de los ordenamientos complejos o plurilegislativos, caracterizado por la convivencia de diversos sistemas legislativos territoriales y por la presencia en su seno de conflictos internos de carácter interregional e interlocal. En particular, la dimensión de los denominados conflictos interlocales debe ser objeto de regulación para evitar que se desnaturalice la esencia misma de los Derechos civiles especiales en los que, como ocurre con el Derecho civil vasco, la pluralidad interna se manifiesta dentro de su propio territorio. La auténtica piedra angular 
sobre la que se construye el desarrollo orgánico del renovado Derecho civil vasco viene asentada en el reconocimiento legislativo de la existencia de una vecindad civil vasca.

Palabras claves: Derecho interregional, conflictos internos, vecindad civil, Derecho civil vasco, Derecho público autonómico.

\section{ABSTRACT \\ A RENEWED VERSION OF INTERNAL CONFLICTS: THE 5/2015 ACT OF BASQUE CIVIL LAW AND POLICY INTERACTION BETWEEN NORMATIVE BLOCKS}

The new Basque Civil Law reopens the doctrinal debate about the need for the nonexistent Spanish Interregional law system (the State legislature) to respond to conflicts arising from the interaction between regulatory blocks, the State should legislate those conflicts. Our State's legal system is considerated very complex and it's called a plurilegislative system, characterized by the coexistence of various territorial legislative systems and the presence within it of internal conflicts of interregional and inter-local character. In particular, the dimension of the so-called inter-local conflicts must be regulated to prevent the disappearance of the special civil rights that, as with the Basque Civil Law, internal plurality is manifested within its own territory. The real cornerstone on which the organic development of the renewed Basque Civil Law is built is seated in the legislative recognition of the existence of a Basque Civil neighborhood.

Keywords: Interregional law, Internal conflicts, Civil neighborhood, Basque Civil Law, Autonomous public law. 